\title{
4. Ontological perspectives and public administration doctrines and themes
}

\section{INTRODUCTION}

In this chapter we revisit a range of key themes in public administration and management, in light of key philosophical ideas introduced in the previous chapters. Our thrust is making a contribution to bring fundamental issues of ontology, as arisen over the centuries in (Western) philosophical thought, into the PA discourse. Differently from other major books dealing with philosophical issues in PA (Raadschelders, 2011; Riccucci, 2010), this book takes as its starting point not the classification of strands of inquiry in PA to then delve into their philosophical foundations and premises, but rather it starts from philosophical approaches, themes and schools, to then delve into some of the implications for the study and practice of PA. In this sense it is quite deductive and ambitious in taking the broad perspective - and in many respects it embodies a very 'European' scholarly tradition and approach.

This chapter deals with themes more pertinent to ontological issues, whilst political philosophical issues are discussed in Chapter 5 and epistemological ones in Chapter 6.

The chapter is structured around key themes. They are listed here, with some captivating questions highlighting the gist and the significance of each theme for PA, to then be briefly introduced in the remainder of this section and discussed in depth throughout the chapter:

- The foundation of the subject capable of moral judgement and knowledgeable assessment of administrative courses of action? The Kantian transcendental subject as a possible grounding of contemporary public governance.

- Deeper societal structures bearing explanatory power? The contribution of the philosophical movement of structuralism to PA by enlarging the gamut of explanatory factors to include structural explanations alongside institutional, cultural and functional ones.

- Social structures and social ontology: revisiting the ontological underpinnings of the relationship between agency (individual freedom) and social structures in social scientific explanations. 
- Power, power, power? Neo-Marxism and Gramsci and the significance of the notion of power for PA studies and practice.

- Caring for the world? The Existentialist Public Administrator.

- Past, present future: do we really understand them? Time in the study and practice of public administration, and implications of the perspective of philosophical historicism for PA.

- It is, it can be or it might be? Necessity and possibility as categories of being (transcendentals), and their significance for PA.

- One human nature or many? How conceptions of human nature may inform the study and practice of PA.

The chapter thus first examines some implications of the Kantian transcendental subject, discussing the extent to which it may provide a foundation to the field of PA. It then turns to discussing societal structures and their explanatory power, through at first revisiting the contribution the philosophical movement of structuralism may bring to PA, to then discuss issues of social ontology and notably the ontological underpinnings of the relationship between agency (individual freedom) and social structures in social scientific explanations. Next, we examine Neo-Marxism and notably Gramsci's always-of-actuality contribution, notably in taking the notion of power to the fore of PA studies (never oblivious to the fact that the bureaucratic apparatus is a centre of power in perennial interplay with other power centres like, most obviously, the political party as the modern Prince - a topic which is further elaborated in Chapter 7 where the actuality of a thinker, Niccolò Machiavelli, inspirational to Gramsci as well as to so many other thinkers across the ages is introduced). In quite sharp contrast with Gramsci's thought, the notion of 'caring' as wrought out in the philosophical stream of existentialism is then discussed in its application to PA: most notably, the profiling of the figure of the 'Existentialist Public Administrator'. The chapter then turns to key ontological topics like the notion of time and the notion (technically called 'transcendental disjunction') of the contraposition 'necessity-possibility', and their significance for the ways in which we study and understand PA; some reflections on the significance of metaphysical contingency and ontologies of possibility (as opposed to ontologies of necessity) are presented. Finally, in a most classic 'last but not least', we turn to considerations about human nature and what this may mean for PA, notably by delving into the issue of (alternative or complementary) conceptions of human nature and how they may inform understandings of PA, a topic which is situated in-between ontology and political philosophy and thence also furnishes a bridge to the subsequent Chapter 5 (as well as to later chapters: the actuality of Machiavelli is in fact manifest here too, since the Florentine writer forcefully argued about the immutability of human nature and its significance for underpinning any claims about the very possibility of learning from 
history, with significant implications for any philosophy of knowledge in the humanities and the social sciences, which we discuss in Chapter 6, as well as for better appreciating Machiavelli's ever-valid teachings, which we explore further in Chapter 7).

\section{KANTIAN TRANSCENDENTAL SUBJECT}

Like for much of modern philosophy, the thought of Immanuel Kant represents a consolidated and well-grounded starting point. Normatively, the foundation of morality and ethics in the rational human subject attempted by Kant aims at providing a universalistic foundation to practical behaviour driven by values: a notion generally indicated with the Greek word praxis, which denotes purposeful action, action shaped by values and sense of direction, the performance of an activity that has moral significance.

This foundation to practical behaviour takes the form of moral law or categorical imperatives guiding the behaviour of each and every human being. Epistemologically, the knowability of phenomena grounded in the very rationality that constitutes the human being furnishes grounding for the possibility of a limited yet founded scientific knowledge that can guide collective behaviour. Although the political philosophy of Kant is a relatively limited area (but we notice that Kant did a very important foray into public, and notably global, governance by making an attempt to outline a system of global governance capable of going beyond the then consolidating Westphalian order: he did it in the essay On Perpetual Peace, 1795, often seen as a philosophical inspiration behind the establishment in the 20th century of the League of Nations and, subsequently, the United Nations) and his general philosophy does not prescribe per se how to build a competent and accountable (Rainey, 2003) system of public governance, it does provide the grounding for argumentation about the criteria and the foundations that such a system might have, by furnishing the underpinning about what is knowable and what is moral for each and every member of the political community. The road from the principle of moral law as Kant formulated it - 'act in such a way that you always treat humanity, whether in your own person or in the person of any other, never simply as means, but always at the same time as end' - to any design prescription about public governance is a long one, and yet a foundational criterion is provided against which to normatively assess any governance system (i.e. public governance systems must be designed and effected in such ways to always treat humanity in every person never only as means but also always as an end); analogously, knowledge of phenomena is grounded in reason in the Kantian philosophical system, and hence he furnishes a foundation for any knowledge claim about social and public phenomena; ultimately, the human being, in the philosophy of Kant, is equipped with both the capacity to know 
and the capacity to act morally. In this sense, any attempt to provide grounding to ethics - and notably for the purpose of our book ethical behaviour in the public service - cannot renounce confronting itself with Kant's attempt to an 'absolute' foundation of moral behaviour (see, for example, Lynch and Lynch, 2006, pp. 71-2 in particular): treat the humanity in your person and any other person always as an end and never only as means - the kingdom of ends. This philosophical underpinning endows the public administrator in the administering of public powers with an overarching criterion against which to gauge her/ his course of action. ${ }^{1}$

The foundation of morality in Kant has been challenged in innumerable ways; possibly the loudest one is that which takes a relativist slant and argues about the impossibility of any absolute and universalistic foundation of morality. However, criticisms have also come from altogether different philosophical angles. In fact a powerful challenge to the Kantian assumption that moral behaviour and considerations of interest and advantage must be entirely distinct, notably when it comes to issues of foundation of public governance, comes from a philosopher active over two millennia before: Plato. As aptly summed up by Bird (2006), if complying with morality does literally nothing to promote anyone's interests, or actually works against them, then this poses a problem for the legitimacy of a political system: even if it complies with criteria of morality, if a political system does nothing for promoting the well-being of its members, what is its rationale, its raison d'être? We return to this point in Chapter 5 .

A philosophical approach that 'dissolves' the Kantian moral subject into 'impersonal' structures is the philosophical movement of structuralism. We turn to this topic in the next section, before delving into the issue of how to combine individual agency (epitomised in the Kantian subject) with social structures in the subsequent section, devoted to discussing more at large the topic of social ontology.

\section{STRUCTURALISM AND PA}

Structuralism is a philosophical approach that puts at the heart the analysis of social structures, notably those deeper, universal and immutable structures which (according to this approach) characterise societies across time and space. As discussed when introducing this movement (see Chapter 3), it is more an emphasis and a focus of analysis than a philosophical system stricto sensu, at least if decoupled from the highly problematic philosophical assertion that 'structures explain everything', that is, that the human and the social, the 'I' and self-consciousness can be entirely dissolved into deeper structural influences. Social structures, in this strong sense, must be distinguished from institutions. Differently from institutions, structures are not man-made (human 
products) - they somehow pre-exist or at least are not amenable to deliberate design; instead, they constitute the bases on which deliberately designed social interventions may be engineered (at least to the extent that structures enable rather than constrain individual freedom - as we have seen, in the perspective of structuralism, individual agency tends to be disparaged).

Structuralism has been employed in various strands in the social sciences, like the field of communications studies, but (to our knowledge) very limitedly if at all in PA. If we ask the question 'to what extent are the findings of structuralism and the analyses of social structures taken into account in PA studies?', the direct answer seems to be 'very limitedly'. This may be due to a number of reasons: possibly because social scientists operating within a structuralism frame are not interested in PA, and/or complementarily because PA scholars are not trained in the kind of analyses carried out in structuralism; or possibly PA scholars have deliberately rejected the kind of social determinism which seems to be entailed by structuralism, that leaves so small room - if at all for human agency and deliberation. Moreover, structural factors may well be reckoned by PA scholars as but one set of explanatory factors, perhaps likened to environmental factors, which can be set alongside functional and cultural factors (to stick to a quite common way of framing 'explanatory factors' in the analysis of public organisations, see Christensen et al., 2007; Christensen and Laegreid, 2018). Thus, it is possibly the recognition of the limits of structuralism by PA scholars to have driven it out almost entirely (to our knowledge) from the field of PA.

However, it would be inappropriate to dispense with structuralism lightly. In fact, it might be argued that, to the extent these limitations are taken into account (and this means notably that alternative categories of factors are weighed in, individual agency is given its proper room, institutions are not dissolved into structures but rather considered as human artefacts that survive their initial creators and have enduring effects on society), the analyses of societal structures worked out in studies in this stream may be a useful addition to the field of PA. They may also improve our understanding of political-administrative institutions in relation to social structures. They may enhance our understanding of individual agency, especially where agency is seen contextually as 'being empowered to do something in particular' rather than as a property of human beings (Clarke, 2013, p. 32), and hence the analysis of structures may be a way to further shed light on what are context and contextual influences (Pollitt, 2013), notably by enabling to better distinguish those features that are universal and immutable across societies - hence a-contextual, as they are a permanent and universalistic trait - from those that are mutable and context-dependent proper. In sum, there seems to be room for some, probably overall limited yet significant, introduction and diffusion of structural(ist) analyses into the field of PA. 
The key issue with structuralism - and the root of the scepticism by PA scholars towards this approach - lies in the suffix '-ism': whether all can be dissolved into deeper structures is an ontological position at odds with any philosophy claiming individual agency - human freedom - is real. If we take the 'soft' version of structuralism: the emphasis on investigating social structures - then we have a philosophical movement which has contributed and can continue to contribute to querying the explanatory power of social structures: an issue which underlies not just sociology (in itself a contributing discipline to PA), but the social sciences more broadly (and thence PA an interdisciplinary field drawing on a range of social sciences).

We have noticed in the treatment of structuralism the ontological assumption about social structures pre-existing human action and underpinning it - and not being man-made. This philosophical point is contested by other authors engaged in efforts to elaborate an understanding of social structures from different ontological perspectives. It is then appropriate to devote our attention closer to the notion of social structure (here more loosely defined than in structuralism, e.g. - following Elder-Vass, 2010, p. 86 - by defining a social structure as 'the causal powers of a specific social group', a group of interacting social individuals, possibly including social norms or social positions), and the related philosophical debate about social ontology, whose roots may be traced also to a philosopher who put centre stage the notion of the man-made (made by the human beings) world: Gianbattista Vico (Chapter 3).

\section{SOCIAL ONTOLOGY}

We have seen in Chapter 3 the original contribution of the Neapolitan philosopher Gianbattista Vico, who famously stated the verum factum principle, that is, that truth is made, by which (in a nutshell) he referred to the idea that, being the social world man-made, it is for this reason also the part of the world that we can know better. Hence, contrarily to what seems to be nowadays common wisdom about the natural sciences setting the paradigmatic form of knowledge that trailblazes, and the social sciences being urged to follow in the trail, Vico (see Chapter 3) argued that we can attain better, and indeed potentially full knowledge, only of the human world (and not of the natural world), because it is the only world of which we can trace the causes for the very reason that it has ultimately been made (been laid down) by humans, throughout the history of civilisations. For this ontological reasons, knowledge of society (as the human-made world) can be attained through multiple means, thereby including imagination, speculation, and pure reasoning - alongside empirical observation and analysis.

In Vico's thought it may also be traced the foundations of the field of social ontology, a notion which only recently has acquired wider currency and has 
become an area of active inquiry. In a nutshell, social ontology may be seen as a branch of ontology, a regional ontology whose focus is on the nature and foundations of social entities: 'the study of what sort of things exist in the social world and how they relate to each other' (Elder-Vass, 2010, p. 4). Its focus is on the constituent or essential properties of social entities, and on the generative mechanisms that bring about social entities.

Durkheim introduced the notion of social fact and the central question of when - under what conditions - a fact is 'social' (Durkheim, 1894/1964 and 1897/1952). He did so also by delving, in a most famous essay, on the nature of suicide: by demonstrating the influence of social conditions on even such most individual act, that is, the choice of taking one's own life, Durkheim aimed to uncover the 'reality' of social facts and their influence - causal power - on individuals' lives. Social entities encompass such entities like: social groups, social conventions, customs and habits of a society, social norms, institutions and organisations, social practices, social processes, social structure. To complement this definition, it can be defined by contrast, rather than by enumeration/illustration, what is non-social: it is considered to be non-social the physical, the biological (e.g. the neural activity of the human brain, or the genetic make-up of the human body), the psychological, and so forth; so, an act of eating together by two or more human beings is social (a social event), the act of the stomachs of each of the two individuals digesting the food is not (it is a biological event) - although the distinction might not be so clear-cut, and conceptually as well as practically it may quite often be problematic to distinguish the social from the psychological, for example to assess whether or not an act can be attributed the quality of being social (e.g. somebody gesturing to offer to shake somebody else's hand) without the corresponding psychological state of the person doing it not being attributed the quality of being social, on the ground that the latter is psychological.

A key debate in social ontology is the one framed in the terms of 'methodological individualism vs holism': that is, whether social facts (practices, events, processes and the like) of any kind can be explained ultimately by direct reference to the actions of its constituents, and the ultimate constituents of social worlds are individuals, or conversely whether macro-social entities carry explanatory power. The question, from a philosophical standpoint, is linked to the issue of the ontological status of social structures. We have already encountered the (radical) structuralism position whereby social structures are conceived of as pre-existing and underpinning human action. An alternative ontological position posits that social structures ultimately only exist within human minds and bodies (a position often associated, e.g. to Giddens, 1984), while the position asserting the reality of social structures as sui generis entities is often traced back to the work of Durkheim. 
The question whether social structures ultimately exist (at least in some sense) only within human individuals, or (again, at least in some sense) outside of human individuals, is an ontological question, notably a question of that regional branch of ontology which is social ontology (the debate has seen leading sociologists being involved, like Giddens 1984; Bourdieu, 1984; Archer, 2003). The related question whether social structures hold causal power (they may explain social phenomena 'on their own'), or not, is also an ontological question. And - of course - the very nature of individual agency, of what is meant when referring to 'individuals acting socially', the capacity of individual human beings to act socially, is also an ontological question evoking the question of what is free will, and what is the scope for individual will to be 'free' (whether human beings can make choices; whether choices humans can make are only circumstantiated and contextualised, or whether there is the possibility for human beings to make 'uncaused' choices, choices unaffected or at least undetermined by social circumstances, although they may then bear significance in the subsequent course of action undertaken by the individual, which will be socially impactful).

Ultimately, it may be noted that the foundations of social ontology lie in ontology tout court. Scholars whose ontology admits the existence of collective entities beyond the individual minds will tend to accept or even forcefully claim the existence of social structures (e.g. in 'impersonal' social structures like in the Marxian/Marxist tradition, Chapter 3). Scholars whose ontology is orientated to place centre stage the individual mind will be inclined to underpin social ontology in the individual (see e.g. the contribution of the thought of Locke - Chapter 2 - on social ontologies centred on the individual, and the ensuing major debate about methodological individualism: for an insightful overview, Demeulenaere, 2011).

Certain approaches to social ontology may claim to be based on relatively undisputed assumptions, but they are not. For example, theories of emergence and the so-called emergentism aim at offering justifications for claims of causal efficacy that are often presented under the label of being 'scientific' whilst ultimately they are - and they can only be - metaphysical. Emergentism is a vast philosophical-epistemological-sociological stream of thought whose clout encompasses both the natural and the social sciences which is predicated on the notion of emergent properties, whereby the whole is more than the sum of the parts and it holds a distinctive causal power which the parts separately considered do not have. So for example the component parts of a vegetable or animal substance do not lose their mechanical and chemical properties as separate agents but at the same time, as an aggregate whole, they also acquire physiological or vital properties in addition; so for example the cell of a living body is more than the chemical components of it, in its distinctive capacity to grow and reproduce itself that it possesses only by virtue of its new order (the 
terms 'emergence' was coined in 1875 by G.H. Lewes drawing from a distinction introduced by John Stuart Mill - see Chapter 3 - between what Mill called homopathic and heteropathic laws - Lewes, 1874-79). A robust and coherent argument for emergentism ${ }^{2}$ to underpin a certain social ontology is worked out by Elder-Vass (2010).

Emergentism is at times presented as a relatively self-evident, undisputed starting point, but far from that, it is instead predicated on certain metaphysical assumptions, and it is totally incompatible with a range of ontologies developed throughout the centuries. For example, the claim that the mental is an emergent property of the biological, which in turn is an emergent property of the physical-chemical, is at times presented as plainly evident, whilst it is profoundly contested and an entirely metaphysical assertion. Let's take the following claim that 'mental phenomena, both when we are conscious of them and when we are not, are somehow produced by the networks of neurons that make up a large part of our brains' (Elder-Vass, 2010, p. 90). Thought is produced by the brain! This assertion is presented as evident - and it may look like this for the ordinary man or woman of the 21 st century accustomed to bowing before 'science' and any claim which is presented as 'scientific' (meaning it is upheld by the current state of the art of knowledge in the natural sciences) - but it is utterly metaphysical, and far from being 'evident'. Let's take the philosophical perspective of Kant or of idealism (in this aligned): from this perspective, the oft-heard assertions like the one above that thought is the product of the brain, and related statements 'the newly developing sciences of the brain will help us to answer [the mind/body question that has preoccupied philosophers since Descartes]' (Elder-Vass, 2010, p. 90) are total nonsense: thinking is being, and brains do not think (active form of the verb), rather they are thought (passive form). For Kant and the Idealists (Chapter 3), like for Parmenides, Heraclitus, Plato and Plotinus, thinking and thought come first, and the horizon of being is the horizon of thought, an understanding of things for which we are indebted to the ancient Greeks (Chapter 2) - and the brain and the neurons are objects of intellection, if they are to be (to exist) at all. What is disconcerting here is not the taking of a philosophical stance, but the ignorance of the metaphysics on which it relies, and the ontologies that it pretends to sweep away without even noticing!

Also the reference in passing to Descartes is misleading: Descartes grounded its metaphysics on the assertion that the material (res extensa, literally, 'the extended thing', the thing whose defining property is to have an extension) and the mental (res cogitans, literally 'the thinking thing', the thinking substance,) are two diverse substances: they, so to speak, belong to parallel ontological orders, hence it cannot be claimed that one 'produces' the other; indeed other philosophers even posed all causal power only in God, treating mutual influences between substances as at most occasional causes, like in the philosophy 
of occasionalism of Malebranche (for more on the philosophy of Descartes and Malebranche, see Chapter 2). Other philosophers, like Spinoza (Chapter 2) even claimed (metaphysically) that there are infinite modes of being, of which the material and the thinking are but two; in fact, for Spinoza the res cogitans and res extensa are just two out of infinite attributes of God-Being (God as the totality of being). And still other giants of metaphysics, like Leibniz, have wrought out metaphysical systems totally incompatible with emergentism: for Leibniz (Chapter 2), reality is made of whole things (monads, see Chapter 2): thus, a human being is not made by the cells, molecules and atoms that compose her/him at a given moment (contra to emergentism); for Leibniz, a human being and a cell are two different objects of intellection, and as such they co-exist next to one another, harmonised by God, rather than 'composing' one another in relations of parts and wholes. As the reader will have noticed, seen from the vertiginous perspective of metaphysical thinking, how problematic apparently unproblematic claims that 'thought is produced by the brain' look!

This is not to say that we do not recognise that emergentism is an important strand in the contemporary philosophy of both the natural and the social sciences - contributing amongst other to complexity theory - yet what we highlight is the lack of philosophical consideration about the ultimate ontological groundings of a(ny) social theory. Social ontology ultimately is based upon and relies on ontology as such (social ontologies are grounded in the general ontology of the philosophy - philosopher or philosophical stream - on which they are built), and ontological considerations have to be treated seriously and explicitly, on their full terms, if social theories are to be provided of their underpinnings.

Based on these premises, philosophy for PA has to engage with social ontology as a field of inquiry, given PA is a social entity and partakes of society. So for example social ontological approaches to conceiving of 'institutions' and 'organisations' as complex social structures that hold causal power beyond those held by 'simpler' norm circles is a major contribution that PA can tap from social ontological thinking, given institutions and organisations, and notably public institutions and organisations, are a central object of inquiry of PA studies (in Simmel's terminology - Simmel, 1955 - an example of a norm circle is the one dictating to individuals in certain societies that 'when you meet somebody, you have to shake their right hand'; the point here is that the properties of normative institution to wield influence on what is 'appropriate' behaviour for individuals, or the properties of organisations to hold causal power by virtue of their capacity to provide coordination of individual behaviours, go beyond those of norm circles, and therefore digging into the social-ontological underpinnings of those additional causal powers - as Elder-Vaas, 2010, Chapters 6 and 7 does - contributes to an enhanced under- 
standing of how public institutions and organisation affect social systems). PA may benefit from the findings of social ontology, notably where this branch of knowledge sheds light on essential properties of social entities, like institutions and organisations, of specific significance for PA themes and problems.

Another key author who - amongst many other influences - can also be seen as lying at the roots of social ontology, and whose thought we have not yet explored in relation to the advancement of the field of PA, is Karl Marx.

\section{NEO-MARXISM AND GRAMSCI}

In Chapter 3 we briefly outlined some elements of Marxian thought. These include, alongside the notions of alienation and class conflict, the perspective of dialectical materialism, according to which history proceeds through contradictions, that is, struggle, of conflicting poles (thesis and antithesis), operating primarily at the level of economic structures, that are solved into superior syntheses. We have also dwelt on the limits in terms of forecasting power of Marxism and Marxian thought, whose predictions simply did not materialise. In particular, we dwelt on the limits of deterministic, linear causality proceeding from the economic to the meta-economic, noticing the interesting interpretation of Marxism provided by the Italian thinker Antonio Gramsci, who elaborated an original synthesis of Machiavelli's thought about the role of the political party as the modern 'Prince' with a two-way interpretation as reciprocal influence of the economic and the meta-economic, noticing how the grasp of power for the political party passes through shaping the dominant values in the pertinent jurisdiction: conquering civil society to then conquer the office of government and the state apparatus, although the state apparatus may also be targeted selectively in order to wield influence over society: we saw in Chapter 3 the case of the Italian Communist Party attempting to hold sway over the public education apparatus to inform pupils' values, and using the work of the so-called 'organic intellectuals' as means to infuse and inform societal values. The general point to be made out of this example is that the bureaucratic apparatus of the state can also, always, be seen as a powerful instrument that can be put to the service of specific, partisan interests, and ultimately as an instrument in the pursuit of power, or for the retention of it, if the actors intending to use instrumentally the bureaucracy are already in power. The Weberian ideal-typical conception of the administration as neutral and subject only to the law (see Chapters 3 and 8) can be, and to some extent will always be, aspirational, but cannot dispel the alternative, however gloomier, vision of it as, potentially at least, instrumental to specific interests (see Arellano-Gault, 2020, for a detailed discussion).

We may now question: what does Gramsci's thought have to say for nowadays discussions of public governance? A major work of translation and 
reinterpretation is necessary, inter alia to incorporate the effects of globalisation processes which were simply out of the picture of Gramsci's reflection. However, lineages, or at least parallels, may be drawn with later approaches that enjoy wide currency in contemporary debates. We here hint at a few of these. First, studies on the links between neo-liberal agendas and the diffusion of the New Public Management (NPM). The argument has been put forward that global capitalism requires independent regulatory institutions for creating trust in markets: these represent a key element in NPM recipes for reforming the public sector, hence, the argument goes, NPM doctrines are aligned to, or even originate from, the interests of organised global capitalism (Roberts, 2010). More broadly, studies have pointed out the links between NPM and the neo-liberal ideology, with some seeing the former as a product of the latter. Although studies like Roberts (2010) draw from different theoretical sources than Marxism, there is a flavour of Marxian acumen in dissecting societal forces and reading complex phenomena through the analysis of the economic processes and notably the lens of the struggle for the control of resources. More specifically, there seems to be much of Gramsci's original interpretation and acuity in reading the doctrines that come to be propounded globally (in our nowadays globalised world) as being at least partly manufactured by economic interests striving to achieve cultural dominance as an instrument to shape the common wisdom and way of thinking (in our case, of the way in which the public sector should be organised) in order to advance their own agenda and priorities. The public discourse about the way in which the public sector should be organised is not an immaculate terrain where free thinkers debate about the best possible conceivable solutions to common good problems, but rather a battleground in which organised interests (which in Gramsci were represented by the political party as the modern Machiavellian Prince) are active alongside free thinkers, and seek to advance their own agenda by achieving dominance in the shared values, locally or more often globally, and hence to shape the organisational form of the public sector in order to most expand their clout. Gramsci reminds us that the search for ideological domination (which we independent scholars see as a danger) may be part and parcel of contemporary public management doctrinal debate (indeed, Gramsci probably would have been a perpetrator of such attempts to ideological domination, were he active today).

This line of intellectual inquiry brings us back to re-considering how power be quintessential to public governance and any understanding of its dynamics. Power in its basic definition as 'the capacity of A to make B do what A wants' as well as in more elaborate interpretations of it. What is especially salient for PA studies is that administrative apparatuses are part and parcel of any power struggle among organised groups (political parties or others, like organised forms of representation of labour - like the trade unions - or of capital). 
Gramscian thought also chimes, perhaps unexpectedly, very well with contemporary, in vogue approaches to public governance like 'governmentality' (originally elaborated by the French philosopher Foucault; and recently critically discussed for applications to public management, see Ferlie and McGivern, 2014; Ferlie and Ongaro, 2015, Chapter 3) or 'metagovernance' (e.g. Baker, 2015), which share the basic guiding idea that 'making people think in such a way that they will behave according to the desiderata of the actors in power' is a very powerful instrument indeed (this is an idea which dates back to the very first attempts to establish 'successful' political regimes since the origin of humankind, but on which authors such as Gramsci provided further original elaborations and interpretations). It seems that taking stock of the bequest of the Marxian apparatus, notably in the elaboration worked out by Gramsci, for the field of PA is a fruitful task yet to be accomplished - although this is an assignment for other books, by other authors.

From structures and collective entities like political parties we now turn to the individual in the most fundamental metaphysical sense.

\section{THE EXISTENTIALIST PUBLIC ADMINISTRATOR}

Although the origins of the movement have to be found in the German philosophers Heidegger and Jaspers, existentialism was popularised particularly by the works of Jean-Paul Sartre. 'Existentialist philosophy was the rage on college campuses and intellectual circles during the 1960 and 1970s' (Waugh, 2006, p. 511) in the US as well as in France and elsewhere, at least in the 'Western world'. The key notion of 'caring' was brought to bear significance, notably on the shoulders of the public administrator who in this perspective should take responsibility over and beyond her/his tasks and duties strictly defined, in order to address the pressing issues of the day (Richter, 1970). The philosophical roots and justification for this approach are to be found in the notion of 'caring' as constitutive dimension of human existence, as well as in the very conception of existence as 'project' and projection towards the future, which are distinctive traits of existentialist philosophy - an authentic life is a life that cares (see Chapter 3). Based on these philosophical notions, the freedom to act of public administrators was evoked and invoked, and public administrators - tenured officials - were encouraged to embark in a call to address urgent societal needs that entailed some form of political activism. The argument was that 'bureaucrats, as they gain more and more knowledge of cause-effect relationships and how that knowledge might be applied, have a social obligation to exercise their free will in the public interest' (Waugh, 2006 , p. 514, emphasis in original). The backdrop was the ample evidence - at least in the US debate - that administrators of the time were quite often not free to use their own judgement, even when remedial actions to clearly per- 
ceived policy failures were widely evident. Indeed, whistle-blowers often paid dearly for their behaviour, and frustration about the apparent unwillingness of top officials to correct programmatic deficiencies, even when solutions were known and available, was the fuel underlying this call to a different role for public administrators (a call which is continuing to be evoked, for example by O'Leary, 2020).

These circumstances seemed to point out that authentic organisations sensitive to the true essence of reality were possible (Waugh, 2006, p. 515) and could be effected by the commitment of public administrators engaging in the authentic life (and professional life is part and parcel of life tout court) that existentialism envisages. It was a 'call to act' grounded in the existentialist philosophy, driven by a possibility to know reality beyond 'technical' value-neutral tools of administration, a kind of knowledge grounded in phenomenology (see Chapter 3 for an overview, and Chapter 6 for applications to the field of PA). This call left a mark on the first Minnowbrook conference on the state of the art of PA, which occurred in 1968 (Marini, 1971), as well as on the conception of the 'new public administration' as later elaborated and systematised by Frederickson (1980). These influences may also be found in the later works of Dwight Waldo, who played a key role in the organisation of the Minnowbrook conference, and in the scientific production, inter alia, of Robert Denhardt and Maria Aristigueta.

An interesting and original perspective to public governance, shifting the emphasis from the administrator (as in earlier applications of existentialism to PA) to the citizen, is developed by Jun (2006). He aims at elaborating a sophisticated synthesis of existentialism with the perspectives of hermeneutics and phenomenology, blended with ethnomethodology, post-modern thinking and critical theory. Jun (2006) is probably one of the most effective spearheads of the relativist school in PA - to which the author adds insightful analyses of the influence of administrative cultures across Eastern Asia (mainly South Korea and Japan) and the West (mainly the US), respectively the places where he grew up and where he spent his professional life. The work has a value-driven and normative tone - as appropriately declared by the author at the outset 'My approaches can be characterized as self-consciously value-laden and normative, rather than nominally value free and descriptive', and this is surely a manifesto of the opposition to Neo-Positivistic approaches, which is a key trait of the interpretivist and constructivist school. A tenet of his approach is the active involvement of citizens in promoting public values, and his book aims at outlining a process for the social construction of public administration in a democratic context - the social construction of a democratic public administration where employee participation, citizen involvement, empowerment and consultation are centre stage, not just as outcome but in the dialectical process of construing a public administration and an administrative theory in which 
the emphasis is on public in the administrative process. Jun's perspective is as much interested in the 'existentialist citizen' as it is in the existentialist administrator. He advocates a social design approach that encompasses both the general public and the governmental sides of public administration. Social design is intended as an evolutionary, developmental, integrative process that should contribute to the construction of shared realities (or intersubjectivities), leading to a process of invention, evolution and self-governance (Jun, 2006, Chapter 4, p. 83 in particular) in order to improve democratic governance without sacrificing the unique individuality or autonomy of each person, and changing organisations by relating the organisation and the individual, the administration and citizens (p. 258) - although it is not always crystal clear what is the difference between the advocated novelty of 'social design' so intended and participatory approaches to public governance. Although Jun's work probably fits the post-modern thinking more than existentialism, his original work is a worthy contribution emphasising the citizens' side of public governance, a contribution which highlights the enduring influence of existentialism in the field of PA. Revisiting existentialism may thus equip with novel perspectives about the responsibility of the public administrator and the citizen in public governance, and may represent a valuable viewpoint from which to look at issues of public ethics and the relationship between citizens and public administrators.

However, the existentialist perspective must deal with the key issue of the foundations of public accountability: to what extent active responsibility by the public official, as far as becoming political activism, is compatible with being held accountable to the public (Bovens et al., 2014)? This issue was present in the debate in the early 1970s, when it was questioned whether such activism by public administrators would meet the conventional democratic test of administrative responsibility; the counterargument was, and is, that not using expertise and experience to address socio-economic problems was both unprofessional and poor citizenship (Waugh, 2006, p. 523). But the issue remains, possibly exacerbated in constitutional frameworks other than the US. It may be argued, notably, that Weberian (and Neo-Weberian) conceptions of bureaucracy, fundamental in PA theory and widely diffused across continental Europe (Rosser, 2018), set up a system of public accountability that may be ultimately at odds with the existentialist perspective of the active, engaged public official: what are the criteria for holding activist public officials to account? How is bureaucratic impartiality (a principle inscribed in the constitution of many countries) compatible with behaviours that trespass into political activism by tenured officials? These are tough questions that remain to be addressed in an existentialist perspective, and the warnings about the dangers of personal passions in public services formulated by Paul du Gay remain in all their actuality (du Gay, 2000). 
Whatever the appraisal that may be given of the dilemmas of public accountability and responsibility in public administration elicited by existentialism, this philosophical school provides a powerful reminder that public organisations and administrative action are ultimately made by free individuals. Bureaucrats and all those wielding responsibility for public services and the public good, elected and tenured officials, policy entrepreneurs or simply engaged citizens, are persons existentially involved and engaged, operating in circumstances that place huge demands on them, also because of the very nature of public services which often deal with issues of the meaning of life vis-à-vis death (the consciousness of death as defining existence is a key tenet of existentialism, see Chapter 3) - one can think of healthcare professionals, or professionals in the sectors of homeland security or defence whose jobs are inherently about others' lives, either because they cure or because they may be demanded to end somebody else's life. It is also a reminder that human existence is never 'an object amongst other objects', but rather constitutively a projection towards the future, a project that can be characterised as (in Heidegger's terminology) 'being-in-the-world' and 'being-with-the-others', and hence caring for the others is a defining trait of each and every human existence. This consideration brings with it a perspective irreducible to any simplification of human behaviour in a public setting as responding only to logics of utility maximisation, or to neutral-impersonal rule following, or to habit-following. Existentialist philosophical thought is for scholars and practitioners alike a powerful reminder that the globally human, existential dimension of the practice of PA irreducibly transcends any modelling or simplification; existentialism reminds us of the practice of PA as praxis: an activity that has moral significance and that in the original usage of the term by Aristotle meant notably a special kind of human activity, the life of the citizen devoted to the political. Stylised models may be of aid for highlighting specific relations between phenomena that may support administrative action, but it is not possible to reduce human agency - and human agency in public services - to those stylised behaviours.

\section{HISTORICISM AND PA}

So far in this chapter we have scarcely devoted attention to time, history and the historical perspective in explaining reality. In Chapter 3 we examined the thought of scholars like Gianbattista Vico, Wilhelm Dilthey and Wilhelm Windelband, and we reckoned the significance of the conceptual tools they provided contemporary social scientists with. These conceptual tools include Windelband's distinction between nomothetic and idiographic accounts and the enduring significance of the latter for the social sciences and for public governance and administration. It also includes Dilthey's notion of the 'sciences of the spirit' as distinguished from the natural sciences and characterised by the 
fact that what they study are expressions of human life. We therefore noticed that the investigator, him/herself a living being, is in a sense identical to the object of the process of knowing, which is the life historically lived by other humans who by means of their collective action effected historical events (the spirit in action), concluding that the sciences of the spirit may in a sense lead to a deeper knowledge than what is enabled by the natural sciences. This line of argumentation had already been anticipated by Vico's verum factum principle (whose literal sense is that 'truth is made'), meaning that we can attain a fuller knowledge of the human world than of the natural world because for the former we can trace the causes not just by empirical investigation but also by means of imagination, speculation, pure reasoning, for the very reason of the commonality of nature between those who made and those who behold the human world, that is, human beings. The human world is, in the deepest sense, 'historical'.

In contemporary PA scholarship there are manifold ways in which 'history' is made to weigh in in explaining administrative phenomena. A large community of scholars work widely in the theoretical perspective of historical new institutionalism (Peters, 1999/2005) - scholars like, to mention but a few, Bezes (2009), Kickert (2011a, 2011b), Ongaro (2009, 2011, 2013), Parrado (2008), Spanou and Sotiropoulos, 2011, Di Mascio et al. (2013, 2017). At another level, Raadschelders (2000) and Rugge (2006), amongst others, have delved into the significance of historiography for public administration, and produced interesting accounts on various profiles of administrative history. Pollitt and Bouckaert have dedicated two books to navigating 'timeship' (Pollitt, 2008; Pollitt and Bouckaert, 2009). From partly different epistemological premises, Asquer, Barzelay, Gallego, Mele and others have advocated 'processual institutionalism' as a methodological approach to the study of public management (Asquer and Mele, 2018; Barzelay and Gallego, 2006, 2010; also Ongaro, 2006), centred on a radical historicism (namely, that knowledge can be attained only of historical episodes in their historical context) which is close to philosophical historicism stricto sensu (whereby being only reveals itself in history, over time, and there is no knowability of things beyond their happening in time).

These are all significant examples of the manifold dimensions along which 'history' and 'time' are brought into the field of PA. However, there seems to be some reticence even in the PA scholars most attentive to the historical dimension to further explore the implications of the philosophical thought of Vico, Dilthey and Windelband and explicitly make the argument about the distinctive nature of the study of 'the world made by humans' as contrasted to the study of the natural world, and about the kind of knowledge that can be attained by the investigator, her/himself human, through investigation of the unfolding of human action in history; recalling the illuminating citation from 
Vico mentioned in Chapter 3: 'the civil world has certainly been made by humans, and it is for this reason that it is possible, and we must, discover its principles within the modifications of our own human mind' (The First New Science, 1725 at: http://www.historyguide.org/intellect/new_science.html). A dialogue between the PA scholarship most heedful to the historical dimension and philosophical historicism might prove fruitful for the advancement of PA (and might possibly also offer novel, interesting and possibly challenging material to professional philosophers in this stream).

There is, of course, a major philosophical theme underlying any debate on history and historicism - the key topic of the philosophical foundations of the very notion of time. It is to this topic we now turn.

\section{TIME IN THE STUDY AND PRACTICE OF PUBLIC ADMINISTRATION}

A limited but very significant stream of works, notably by Christopher Pollitt and Geert Bouckaert (Pollitt, 2008; Pollitt and Bouckaert, 2009; Bouckaert, 2007), have addressed the theme of how the temporal perspective is treated in public management and policy. Pollitt (2008) proposes a frame for navigating 'timeship', tackling inter alia the crucial issue of the appropriate time horizon to be adopted for the proper understanding of administrative phenomena. Bouckaert (2007) has delved into manifold cultural conceptions of time and how they affect public administration and management (whereby, e.g. certain culturally construed notions of time define it as 'linear', evolving from a beginning to an end, or at least moving from a neatly distinguished 'before' to a sequence of 'afters'; other notions of time conceive of it as circular, returning to the same, or similar, point after having effected a cycle; other conceptions of time separate neatly the spheres of the past, the present and the future, while others consider past, present and future as at least partly overlapping; and so forth). The specific take to the topic that this book deploys is that of considering the implications for public administration studies of revisiting certain foundational issues lying in the very notion of 'time' as it has been debated in philosophical thought.

The French philosopher Henri Bergson famously introduced the distinction between the 'spatialised' time of physics and time as duration, the latter being the time of life, according to his line of argumentation. In the Bergsonian perspective (see Chapter 3 ), the past is conserved and kept in its entirety into the present: time is the tissue of which each living being is made, as is the universe as a whole, although not inanimate portions of it (Bergson, 2005). Life for Bergson (like for Heidegger in this respect, although within a different philosophy) is continued projection towards the future by plunging oneself into the present, and accumulating progressively every instant of the lived 
life into our past, like a snowball that continuously grows along the way and conserves in itself the totality of the snow that it has encountered. This is the time people live, according to Bergson. If we accept this ontology of time, then it follows that this is the real, lived time of public administrators at all levels, as probably most ethno-methodologists, and more widely students employing techniques fit for reaching out in a more holistic way to administrative phenomena, would acknowledge. Such distinctions, indeed contrast, between the 'spatialised time' of social phenomena when they are studied 'from the outside' and the lived time as duration when plunging into social phenomena, has been widely employed in many domains across the social sciences (e.g. in communications studies, see Kember and Zylinska, 2012), but yet its potential has so far not been reckoned (at least to this author's knowledge) in discussions about change and continuity in public administration and governance; at the very least, this attention to the notion of time adopted is not made explicit and mainstreamed as a methodological point in the vast majority of the works in the field of PA. However, it is tautological to state that the time of life is the one practitioners experience in acting (administering), and hence it may be queried - on the foundational, ontological ground of the underlying conception of time - the kind of fit currently existing between the knowledge supplied by the PA scholarly community and the demand for employable knowledge by those practising public administration. Part of the often-evoked misfit between scholarly knowledge on offer and the knowledge demanded by practitioners may also possibly lie in the implicit underlying conception of time employed by the two groups respectively in the creation and usage of such knowledge.

A philosophical perspective of central significance for any analytical frame in which the past bears explanatory power is the dialectic approach, famously associated with the great German philosopher G.W.F. Hegel (see Chapter 3). In this perspective, the thesis and the negation of it (antithesis) do not annul each other, but rather they are synthesised dynamically (that is, over time) in a superior unity of the opposite determinations, in which they both continue to live, albeit transcended in their initial reality. A dialectical process being in operation has sometimes been evoked in longitudinal studies in public policy and management. The debates on 'the trajectories of public management reform' (nourished by seminal works like Pollitt and Bouckaert, $2000,2017)$ is one sheer example, notably when they introduce the model of the Neo-Weberian State (Pollitt and Bouckaert, 2004, 2000/2011; Drechsler and Kattel, 2008; see also Ongaro, 2009, Chapter 7), which - we suggest implies the thesis-antithesis-synthesis logic that is predicated of the dialectical method for analysing historical progress: the thesis is the Weberian model, the antithesis is the managerial model, and the Neo-Weberian model is the synthesis (albeit 'progress' is here detached from the inherent determinism, driven by a logic of necessity, that can be found in Hegel, as well as in significant por- 
tions of the philosophical stream of historicism). In short, a Hegelian conception of time may be deemed to underpin explanations of public management reform trajectories pointing to a Neo-Weberian synthesis. In Hegel's dialectical perspective, after one pole and its contradiction (thesis and antithesis) have occurred, history is no more the same. Evolution of history, for Hegel, is like a helix: there is both circularity in the movement from thesis to synthesis via the antithesis and progress or development, an overall 'trajectory'. For Hegel, time constitutes things - it's not just merely the backdrop against which things appear (come to being) and disappear (return to non-being); therefore, after having occurred, two poles will not repeat any more, they will not re-present themselves identical.

Adopting a dialectical philosophical stance also entails rejecting any model of history as the oscillation between two poles: as a continued alternation between two poles that recur fundamentally unchanged, a philosophical position which brought to the extreme evokes the eternal recurrence of the same (which is another philosophical stance with a very long history whose roots can be traced back to a stream in ancient Greek philosophy), brought again into the philosophical debate of the 20th century by Friedrich Nietzsche (Chapter 3). Hegel's philosophical position constitutes a challenge to the extreme position of the eternal recurrence of the same but also more generally to "pendula approaches' whereby history repeats itself in similar guises. Such pendula approaches form part and parcel of much of the common wisdom in PA, as it has been shaped by 'classic' works, like Simon's 'proverbs of administration' (1946) or Hood and Jackson's administrative arguments (1997). These works do not claim that administrative history actually oscillates between poles; instead, these studies were pitched at the level of administrative argumentation, noticing how prescriptions often come in opposite, potentially contradictory pairs (Simon, 1946), or how 'new' doctrines on public sector organisation may actually embody old positions that show up again in new guises. Based on these and other considerations, some studies have taken the longer-term perspective and, by means of time series or other techniques, have pursued the objective of detecting patterns in administrative doctrines and practices, and notably of detecting whether a pattern of alternation between two poles may have explanatory power. These are empirical studies, but it may be noticed the ontological assumption of the search for such patterns is that one state of affairs 'dissolves' when the pendulum swings, to then 'reappear' when the pendulum sways back. Although this logical passage may have gone unnoticed, this is not an empirical datum but an ontological assumption, and one that runs counter to the Hegelian dialectical perspective: for Hegel (and for historicism at large, as well as for other philosophies) the passing of time forbids returning to the same state of affairs, in the most fundamental sense, because the past is incorporated into the present and is constitutive of it. ${ }^{3}$ In short, helix-like or pendula-like 
conceptions of administrative change are predicated on different and contrasting ontologies. As argued throughout this book, making such ontologies more explicit, and debating their implications also for empirical scholarly work may benefit the reach and depth of PA as a scholarly endeavour.

The Hegelian conception of the dialectical evolution of history also poses a big question for the foundation of the theoretical perspective of historical (new) institutionalism (HI). $\mathrm{HI}$ is a theory to explain the enduring influence of past choices over contemporary institutions and policies (Peters, 1999/2005; for a later review, Ongaro, 2017). The foundational question in HI lies in the explanation of causality: why do past choices about the structure and processes of government cause present effects? What is the causal foundation of path dependency? One theoretical justification for HI is grounded in the perspective of the 'logic of appropriateness', whereby institutions are deemed to shape what is considered appropriate by decision-makers, and hence constraining the boundaries of what is considered to be feasible or opportune by decision-makers. Another theoretical justification for explaining path dependency lies in rational choice and argues that institutions shape the opportunity structure within which decisions are made. But both causal logics presuppose that the past is influential because it has produced something that has remained and is 'present' at the moment the causal effect is produced: institutions remain, they continue into existence, and it is their very presence to be the causal factor. Without that cause which is 'present', no effects would be produced. This is a widely held assumption in scientific - including social scientific - discourse, yet things might be more complicated. ${ }^{4}$ The assumption that only what is present may have an influence (it may be the cause of something) is a specific epistemology based on distinctive philosophical foundations. But other philosophers thought differently: Hegel and Bergson, albeit from very different angles, both point to the past being influential in a more constitutive way: the totality of the past constitutes what we are (what everything is) and construes and enables the possibility for individually and collectively projecting ourselves towards the future. This applies both to individual lives (Bergson) and to broad, collective historical processes (Hegel): the question then becomes whether it applies to institutions as well.

In a riposte to those who claimed that 'the past is dead', the novelist William Faulkner in Requiem for a Nun puts into the mouth of a citizen of the fictional city of Jefferson, Mississippi, the following comment: 'The past is never dead. It's not even past' (cited in Sansone, 2009, p. xv). Time may matter in a more fundamental sense than too often held in scholarly inquiry, and also by those who are most heedful to bringing time and the temporal dimension into social science explanations (Abbott, 1992a, 1992b; Pettigrew, 1990, 1997; van de Ven, 1992, van de Ven and Poole, 1990) and notably in the field of PA (Asquer, 2012; Barzelay and Campbell, 2003; Barzelay and Gallego, 2010; Bouckaert, 
2007; Ferlie and Ongaro, 2015; Mele, 2010; Mele and Ongaro, 2014; Ongaro, 2006; Pettigrew et al., 1992; Pollitt, 2008; Pollitt and Bouckaert, 2009).

If the totality of the past is conserved, is maintained and shapes the present, then this very consideration poses a fundamental challenge to all epistemic approaches (and notably for the purposes of this book those applied to studying administrative phenomena and public governance) that take the move from the apparently innocuous and self-evident assertion that phenomena can be studied by setting a system 'at $\mathrm{t}=0$ ' (or 'given $\mathrm{t}=0$ ', that is, resetting time to zero), because $t$ never equals zero, according to these philosophical perspectives.

Another challenge comes from the conception of time as ecstasy elaborated by Heidegger ('ecstasy' in the etymological meaning of 'staying - lying outside of oneself', see Chapter 3). For Heidegger, the future is projecting ourselves towards what will be; the past is stretching ourselves towards a situation of fact to accept it, and the present is lying outside of oneself to stay next to the things. The question thus becomes: what do we ultimately do when we study past cases? For Heidegger, more than detecting causal nexuses, we are ultimately 'accepting' them - which is quite a different stance. What do we ultimately do when we 'draw lessons' for the future? The drawing of lessons is but a part of a broader constitutive, existential dimension of projecting out of ourselves, in a Heideggerian perspective. What do we ultimately do when we apply knowledge to present situations? For Heidegger, application of knowledge is but a part of the fact we are 'caring' for things, we are lying outside of ourselves to stay next to the things. The big problem raised by Heidegger is that the time of science (both the natural and the social sciences) is inauthentic, while the life we live and experience together with the others occurs in the authentic time whose tissue is the projecting of the individual existence outside of oneself: hence an irremediable gap between the scientific-technological knowledge accumulated (in our case, by the administrative sciences) and the practice (praxis) of - in our case - administration and administering.

However, to strike a more positive note to end this reflection and look towards possible bridges connecting this apparent chasm between philosophical notions of time and the everyday practice of PA studies, certain approaches in PA may be more sensitive than others to this issue. For example, Barzelay and Campbell's treatment of time in the book Preparing for the Future, an account of strategic visioning in the US Air Force (Barzelay and Campbell, 2003), is based on a processualist approach that owes much to such philosophers as Mary Parker Follett (herself a major contributor to organisational studies alongside philosophical studies; see Feldheim, 2006; Stout and Love, 2015; Ongaro, 2016), and represents an interestingly distinctive approach in the field of public management. In a similar vein are the works by Asquer (2012), Barzelay and Gallego (2010), Mele (2010), Mele and Ongaro (2014), Ongaro (2006), Pettigrew et al. (1992) - authors active in public management 
drawing from works in the broader social sciences by scholars such as Abbott (1992a, 1992b), Pettigrew (1990, 1997), Pierson (2004), van de Ven (1992) and van de Ven and Poole (1990).

\section{POTENTIALITY AND ACTUALITY}

In Chapter 2 we briefly hinted at the endurance of the thought of Thomas Aquinas over the centuries. His thought and the tradition of the Scholastics is a continued and highly influential presence in the philosophical debate. In the 19th and 20th century, the neo-scholastics is associated with philosophers such as Desiré Mercier (1851-1926), Jacques Maritain (1882-1973), Étienne Gilson (1884-1978) and Francesco Olgiati (1886-1962). Two notions widely elaborated within this tradition are worth plucking for the purposes of this book. The first one is that of metaphysical contingency and the actus essendi (act of being); the second one is that of analogy. We have already discussed the latter in Chapter 3 in relation to - and as a conceptual tool for the critique of - Popper's philosophy of science. Here we discuss (briefly hint to) some implications of contingency metaphysics.

In Aquinas philosophy, things are contingent in the most metaphysical sense: all entities of the world, all events of history may be but also may not be. They have the potential to exist, but their existence is contingent (only in God does essence also entail existence). This is a crucial metaphysical transcendental, defining a type of ontology based on the category of the possibility. Other ontologies we have encountered claim the opposite: that all things that are, necessarily are (like in Hegel, who derived this notion from the philosophy of Spinoza - see Chapter 2; as we have seen earlier, Nietzsche also theorised the necessity of being up to the point of predicating the eternal recurrence of the same).

Within the realm of the category of possibility, the potentiality versus actuality distinction is crucial. Put simply: the potential for a thing to exist is different from the thing actually existing. To show the practical implications of this philosophical category, it is argued that a proper consideration of this philosophical theme may shed light on key topics in public management like the 'can it work?' debate: can NPM reforms work in context ' $X$ '? What happens if doctrines ' $\mathrm{Y}$ ' are transferred to context ' $\mathrm{Z}$ '? How can a practice ' $A$ ' that has proved successful (generated the effects ' $\mathrm{B}$ ') under circumstances ' $\mathrm{C}$ ' replicate its effects under circumstances ' $D$ '? And crucially, could the same effects ('B') have been obtained otherwise (caused by a practice ' $E$ ' rather than ' $A$ ')? And could ' $A$ ' have not generated the effects ' $\mathrm{B}$ ' under circumstances ' $\mathrm{C}$ ', maybe due to chance events? These and many similar questions are considered very 'practical' questions, and yet their philosophical premises raise hugely problematic issues. Key to these issues is the question of the potentiality- 
actuality distinction in philosophy, and whether the underlying ontology is one based on the transcendental category of 'possibility' or on the category of 'necessity'. Put, again, very simply, if one adopts an ontology of necessity the answer to the question above - 'could ' $\mathrm{A}$ ' have not generated the effects ' $\mathrm{B}$ ' under circumstances ' $\mathrm{C}$ ', maybe due to chance events?' - is ' $n o$ ', whilst if one adopts a contingent ontology is it 'yes'.

Similar considerations apply for counterfactual argumentations, which try to grapple with the crucial questions: what would have happened otherwise? What if (things had gone differently)? Sophisticated techniques have been developed in the social sciences to come to grips with these questions, like the synthetic control methods, which aim at providing a systematic way to choose comparison units in comparative studies by using a combination of comparator units for construing what 'would have happened' in the absence of a certain policy intervention (Abadie et al., 2015). The key point to notice here is that such methods, to be meaningful, presupposes an ontology of possibility, rather than one of necessity. A point with huge implications, to which we can only hint here, as we do in the following section.

\section{OF NECESSITY OR OF POSSIBILITY?}

The idea of the necessity of being (all that is, necessarily is) was introduced, at least in modern philosophical thought, by Baruch Spinoza (see Chapter 2) and then came to dominate the philosophical system of Hegel and many of his philosophical heirs (see Chapter 3). The rejection of the Hegelian system goes hand in hand with the contestation that it is possibility to be the overarching category of being (as vehemently argued by the philosopher Soren Kierkegaard): that things that are, might also have not been, and vice versa. ${ }^{5}$

We argue that across the social sciences research, and notably for the purposes of this book, the PA research, the very basic stance towards this fundamental ontological issue - whether necessity or possibility is the overarching category of being - draws a major differentiating line in terms of the fundamental stance of the researcher. For example, when Pollitt and Bouckaert in their study of the trajectories of administrative reforms and their antecedents and consequences argue for 'chance events' playing a role (Pollitt and Bouckaert, 2004, 2000/2011), they seem to recognise more explicitly than other authors their basic stance about possibility as the ultimate category of being.

If we assume Popper's perspective that it is ontological assumptions to drive scientific inquiry, the question is: in the scientific research in PA, what ontological perspective drives the investigator when studying the administrative phenomena? Is the investigator assuming that what is observed is ultimately inherently necessitated (ultimately, it could not have been diverse ${ }^{6}$ )? Or, is 
what is observed assumed to ultimately be just one possibility out of many; that is, ultimately, things could have been otherwise? Chance, free will, otherness-transcendence (what is outside the immediate horizon) all weigh in in this latter ontological perspective, which will tend to see the world as, literally, a world of possibilities, while they tend to be ruled out in the former, which will tend to see the world as tantamount to one big chain of necessitated causal relations. The question arises as to what is the role of the PA scholar in either world? In the latter (a world of necessary causation), the PA scholar will probably resemble more the detached observer, not engaged with the world (because the world cannot be changed, if it is necessitated), focused on discovering at least some proximate rings of the huge causal chain of which the world is made. In the former, the PA scholar will be more akin to an engaged student, who sees the world as malleable and which can be shaped by human beings, through the exercise of free will and intent (along an intellectual line from medieval thought and the role of intentionality in human actions to modern-day existentialism): a vision of human liberty enacting purposeful designs to change the world - and public governance and public policy within it - also thanks to being equipped by the findings of PA research.

\section{BETWEEN ONTOLOGY AND POLITICAL PHILOSOPHY: CONCEPTIONS OF HUMAN NATURE AND THE MANAGEMENT OF PUBLIC SERVICE ORGANISATIONS}

A major object of philosophical inquiry of high significance for the field of PA as well as across the social sciences is the investigation into the main traits of the notion of 'human nature', a central yet at least partly elusive concept. The topic is located across the philosophical branches of ontology, on one hand, and political philosophy, on the other hand. It pertains to ontology insofar as the investigation into the reality of humanity is part and parcel of the inquiry into the nature of being, and it pertains and it is in a sense the starting point for political philosophy as well as ethics, since the questions about 'how to live together' and 'how to live well', which are, respectively, the central question of political philosophy and of ethics (Chapter 1), rely on the understanding of human nature to be addressed, and notably the question about 'how to live together' cannot be addressed unless the question of the ultimate nature of the beings who have to live (well) together, that is, humans, is also addressed; as we shall see in Chapter 5, an inquiry into human nature is exactly the starting point of Plato's argument about the 'common good' as the criterion that provides legitimacy to a political system. The very possibility of using the term 'nature' and talking of human nature, which ultimately means talking about the 'essence' of the object of study, is premised on the analyses carried out by 
the philosophers Vico and Dilthey, who identified the distinction between the natural sciences, on one hand, and the 'sciences of the spirit' and the study of the 'man-made' world, the world made by human beings, on the other. These philosophers highlighted the very possibility for scholars and beholders of the human world to gain a deeper understanding of it, for the very reason that the subject of the process of knowing, her/himself a human being, is in a sense identical with the object of the process of knowing: the human-made world. It is for this reason that talking about the 'nature' of the object of study does not appear inappropriate nor 'unscientific', quite the contrary.

Bringing this topic to the forefront of research in the field of PA is not an altogether novelty: an explicit and very insightful attempt to probe into the link between human nature and the management of public services (notably the performance of public services) is provided by Talbot (2005), who elaborates on the implications of the human being characterised as 'the paradoxical primate'. In his work, Talbot takes the move from the (ontological) consideration that human beings are inherently paradoxical (hence the human being as the 'paradoxical' primate) for drawing implications for the ultimate foundation and justification of the criteria against which to assess the performance of public organisations and public programmes.

Considerations about human nature and whether and how it enables to uphold certain values also suffuse practitioners' understandings of PA. For example, the code of conduct of the British civil service asks civil servants to always uphold four core values: ${ }^{7}$ integrity (defined as 'putting the obligations of public service above one's own personal interest'), impartiality (defined as 'acting solely according to the merits of the case and serving equally well governments of different political persuasions'), honesty (defined as 'being truthful and open') and objectivity (defined as 'basing one's advice and decisions on rigorous analysis of the evidence'). (It may be noticed the call to the highest standards of both intellectual objectivity and intellectual honesty, a notion very much tied to the 'stewardship' conception of the UK civil service: civil servants as stewards of the government of the day, by 'serving equally well governments of different political persuasions'.) While the status of these values may be questioned (whether they are a basic standard, for civil servants never to be found faulty of), or rather are more an aspiration, urging civil servants to always strive in the pursuit of these obligations, they surely raise questions about whether human nature enables or hampers the attainment of such a high-level bar of expected behaviour.

What arises from this brief review of the topic is that issues of values (public values) and issues about human nature and whether and how it may - or may not - enable to uphold certain values are centre stage for any inquiry into the foundations of PA. 
Hodgkinson (1978) sets out a highly significant attempt to develop what he calls 'a philosophy of administration', where by administration he basically means the executive function in all organisations, public or private. An important preliminary qualification here is that that the scope of Hodgkinson's book is different from this one: the difference between Hodgkinson's work and this is that the present book is about public organisations, while Hodgkinson is interested in examining human nature - its essence and its behaviour - in every organisation, public or private, and sees organisations and the organisational phenomenon as a crucial field of the social space where human life takes place. Moreover, the meaning in which the term 'administration' is used is different between the two books: Hodgkinson by administration intends the exercising of the executive function in an organisation, whereby administrating is intended as 'the art, science and profession' of making decisions in organisations (broadly intended it is tantamount to the managerial function in an organisation); this book is about 'administration' intended in a different sense, as a dimension of the public sphere, a reality of the living together of human beings in a political system endowed with a public administration. Finally, Hodgkinson's work aims at proposing a philosophy of administration: the function of the preposition 'of' is here crucial, as his focus lies in working out a synthesis of diverse (at times disparate) philosophical positions in order to attain an original synthesis which aims at constituting a standpoint on the phenomenon considered (see Chapter 1 on the distinction between philosophy 'for' and philosophy 'of' public administration). With this important qualification in mind, Hodgkinson's work is relevant for the purposes of this book insofar as he develops on a crucial ontological issue, the human nature, and applies an understanding of human nature to the theory and practice of organisations, thereby encompassing the public organisations. There is thus an overlap with the remit of this book to the extent that: (a) Hodgkinson's findings and theoretical propositions may be applied also to public organisations (as a subset of the category of organisations in general, though his focus is always on the individual organisation rather than on, for example, the broader public administrative system, or public governance more widely, which are instead part of the object of study of this book); (b) the executive function is one aspect of central significance of public administration (although not the only dimension of PA); and (c) it is kept in mind that Hodgkinson aims at advancing his own philosophical propositions (philosophy of administration), rather than exploring how philosophical thought in its varied streams may be brought into the field (philosophy for public administration). Having set out this important clarification on the differences between Hodgkinson's work and this one, we can now turn to review the original contribution made by Hodgkinson's 'Towards a Philosophy of Administration'. 
Hodgkinson's starting point is that administration (as the performance of the executive function) is both an area of applied logic (practical reasoning, in Aristotle's framing of the issue) and an area where the exercise of value judgement is quintessential. Thence, philosophical knowledge and understanding is part and parcel of the essence of the activity of administering an organisation. Hodgkinson very effectively reviews a disparate literature on organisations and decision-making in organisations to pave the way for the core of his analysis: the relations between the perennial human nature as it embodies over the ages in individual human beings, on one hand, and organisations as the field where administrative action (the exercise of the executive function) takes place, on the other hand.

A key tenet of his approach is the distinction between 'is' and 'ought to be', a key philosophical notion which we have encountered and examined. Based on this notion and the centrality of values in human action, and hence also in human action within organisations, Hodgkinson outlines an analytical model of the concept of values, which places values for human beings at three levels; simplifying a lot, at one level we can find values associated to 'pleasure' (affective and hedonistic dimension: what the individual 'likes'); at another level values which are assessed for their consequences or their appropriateness (from social consensus to desirability of expected outcomes of social action); at the third level values whose foundation belongs to the moral order or on religious or faith grounding: the 'principles', like the Kantian categorical imperative, or the guiding imperatives that derive from adhesion to a religion or a faith. Whilst this tripartite model of human motives may be criticised on manifold groundings (as an even very rapid skimming of the pages above in Chapters 2 and 3 might indicate), yet the purpose of 'modelling' value-based human behaviour for the objective of understanding human behaviour in organisations is laudable and part and parcel not just of a philosophy of administration but valuable starting point for a philosophy of public administration too, and calls for such efforts are most welcome.

An especially brilliant chapter in Hodgkinson's so insightful book is Chapter 9 (pp. 151-70), which delves into the pathologies of administration, that is, the pathologies inherent with the dynamics whereby human beings strive to reach the apex of organisations, to be 'successful' in their professional life, whereby the measure of such success lies in enjoying the concentration of power that can (allegedly) be found when attaining the top posts, when becoming administrators at the top of an organisation. It is here that philosophical perspectives are at the front of the analysis and make Hodgkinson's study so distinctive and penetrating.

His insights into the pathologies of organisations take the move from the dilemmas of the Platonic guardians: those with the virtues for wielding power do not have the predisposition to pursue it: they would rather withdraw from 
power, not strive for it, and compete with the aggressive people to attain it. Ambitious men and women, not the philosophers, will have the drive to achieve success in organisations (as in the saying: 'nice guys finish last'). This poses a dilemma for the administration of any organisation, if human nature is such that those less versed in the art of administering it are the same who strain most to reach the hierarchical apex, then negative or adverse selection may be the natural equilibrium for an organisation. This argument may be further reinforced if we assume the Machiavellian prince (Chapter 7), or indeed the stylised version of it depicted in the following passage, as the model of human nature:

a thoroughgoing Machiavellianist will righteously scheme for the betrayal and downfall of his superiors and will use his peers and subordinates as means. Not, as Kant would have it, as ends in themselves ... Yet withal he will not let this be seen; it must not be perceived or at all obvious in any way that this is going on: quite the opposite, especially in a culture which elevates the values of sociability, co-operation, and conformity. It must be well-concealed and disguised ... He will necessarily become adept in all the arts of human relations manipulation and acquire the full panoply of political skills, arts and skills ... he may even succeed in deceiving himself by resort to several species of rationalization: he is doing it for the family, his dependents or, even, for his organization, his country or, pseudo-philosophically, because if he doesn't somebody else (much worse) will. (Hodgkinson, 1978, pp. 160-1)

Another pathology of organisations starts from another trait of human nature: aggressiveness. The problem here lies in the fact that aggressiveness may be seen as a feature facilitating the climbing of the organisational ladder: 'One is unlikely to climb far in the organisational hierarchy without it' (Hodgkinson, 1978, p. 162). The problem becomes organisational when this trait of climbers in organisations is coupled with the nature of administrative roles as authoritative ones, that 'are functionally dependent upon the attitudes of compliance and the zones of acceptance or indifference' (Hodgkinson, 1978, p. 162); the issue is that:

compliance can be construed as a way of abdicating responsibility ... Conscience can be suspended [so that] 'any competent manager of a destructive bureaucratic system can arrange his personnel so that only the most callous and obtuse are directly involved in violence. The greater part of the personnel can consist of men and women who, by virtue of their distance from the actual acts of brutality, will feel little strain in their performance of supportive functions. They will feel doubly absolved from their responsibility. First, legitimate authority has given full warrant for their actions. Second, they have not themselves committed brutal physical acts'. (citing Milgram, 1974, p. 122) (Hodgkinson, 1978, pp. 162-3) 
A consideration which brings us to another key aspect of organisations: that they may act as decoupling individual morality from 'organisational morality':

formal organizations are in certain critical aspects antagonistic to ordinary morality ... This antagonism comes about because of the organizational value of rationality and the nomothetic principle of depersonalization. In the complex bureaucracy, individuals are not whole persons but role incumbents ... they are parts, replaceable and substitutable ... Morality, in glaring contrast, is a function of total personality and overflows any role [however] Organizational goals combined with rational procedures for their attainment ... make organizational life analogous to chess. Within the game there are no 'right' or 'wrong' [in the sense of morally just or unjust, our note] moves, only those of more or less efficacy given the set system of rules which cannot in itself be challenged ... even the administrator is not an author of acts but an agent, one who does things in the name of others ... the agent is not personally or morally responsible for the acts which are under the authority or the authorship of the collectivity ... and outwardly benevolent organizations can become latent collective forces of evil. (Hodgkinson, 1978, pp. 172-3)

We find these insights provided by Hodgkinson into the nexuses amongst human agency, responsibility, and organisational malevolence enlightening (echoing here issues of responsibility in organisations, and notably in the execution of evil in organisations - 'the banality of evil' - which are also raised in the section on the existentialist public administrator, earlier in this chapter).

Other pathologies of organisations include busy-ness and superficiality; pseudo-machismo and anti-intellectualism; the cult of leadership (till the emperor is shown to be in the proverbial underwear); the over-infusion of organisations with values (notably a characteristic of military organisations, which necessitate to counter their nature of agencies of naked power for the nation state).

What is enlightening of the approach worked out by Hodgkinson is that he takes as starting point philosophical conceptions of human nature, to then combine them with the findings of social sciences and notably managerial and organisational studies, in order to work out the implications for the value-laden problems of the performance of the administrator, that is, the 'executive' or 'leadership' role in organisations (Hodgkinson also dedicated later works to the study of leadership).

Hodgkinson's work highlights a number of dimensions which are crucial to any attempt to link philosophical conceptions of human nature and the study of organisations: it highlights that values judgements are inherent in making decisions in public organisations (and private alike) and that decision-making is not and cannot be a value-free activity. This consideration points on one hand to the significance of moral philosophy for an understanding of the issue of individual and organisational responsibility, on the assumption that the human being belongs not just to the natural order, but also to the moral order (as out- 
lined in the opening of this chapter in reference to Kant's moral philosophy). On the other hand, the consideration of decision-making as a value-charged activity also points to the issue of the motives of human behaviour as key drivers for understanding people in organisations; for example, in Chapter 7 we shall see the significance that pride takes as a driver of human behaviour in Machiavelli's thought, or the emphasis the Florentine writer places on the desire to enter History (with the capital ' $\mathrm{H}$ ': entering History in order to be remembered forever) as a key driver for human beings when aspiring to the highest public office: the amoral, if not outright immoral, drivers of human nature.

The quest for models of human nature ('model of men') has been driving philosophical inquiry over the centuries, a stream of inquiry rife with contention which, in the end and after centuries of harshly debating, may have led to exhaustion - and outright scepticism - about the value and usefulness of working out 'a model of men', in Herbert Simon's memorable phrasing. It is interesting to point out that prominent social scientists have tended to refrain from entering the field of modelling human nature and rather prefer to restrain their claims to the level of the (working) assumptions underpinning a paradigm of research in the Kuhnian sense (Chapter 3): for example, Raymond Boudon gives his theorisation of 'ordinary rationality' - as opposed to Simon's bounded rationality and other rationalities theorised about - the ontological status not of a philosophical statement describing the essence of men, but rather of a postulate of the social sciences: "My claim that the social actor should be treated as rational, in the sense of the Theory of Ordinary Rationality, is a postulate for the social sciences, not a philosophical statement describing the essence of men' (Boudon, 2011, p. 48, emphasis in original).

In this sense, the question arises whether social scientific 'motivation theories', which have been wrought out over the decades and represent an area of major inquiry in organisation studies, suffice at least to describe the observable behaviour of human beings in organisations, that is, whether debates on human nature can be boiled down to motivation theories for the purposes of understanding people's behaviour in (public) organisations, and for related purposes like designing 'adequate' compensation systems that reflect (to adopt a wording on which there seems to be some general agreement, at least terminological) the extrinsic, intrinsic and pro-social dimensions of people's motivation in organisations. We would argue, as is the case for other 'modern social scientific disciplines' employed for the study of PA, that here too there is a philosophical residue (see Chapter 1): whilst social psychology and organisation studies have in most respects 'settled down' and built their home as an autonomous science with their problem statement, research objectives, and consensus over the methods, and notably as part of it have set up what we refer to as 'motivation theory in organisations', the research topic of human motives 
and what drives human behaviour (thereby including human behaviour unfolding in organisations as a part of it) cannot be stated in a totally uncontested way, and there is a 'plus' about the understanding of human behaviour that transcends what can be achieved by means of the application of the 'scientific method'.

Indeed, as it often happens with core philosophical issues, we doubt that the thirst for knowledge about the 'ultimate nature of human beings' will ever be quenched, even more so when the area of inquiry is so ripe with implications for questions of such saliency like 'how to best organise society and the realm of the political'. Moreover, to the extent a field of inquiry does not content itself with observing social phenomena (as could be the case for sociology) but is also about intervening on society for changing it and making it in some sense 'better' (as is the case for PA as public management), the intertwining of 'is' and 'ought to be' will inevitably call for grounding in philosophical arguments any claim that is being made about how to manage people in public organisations and administer public policies and public services.

\section{NOTES}

1. It should here be noticed that the Kantian foundation of morality is not utopia, contra to what is claimed in Garofalo and Geuras, 2015. We discuss the normative and regulatory functions of utopias in Chapters 7 and 8 , starting from the work of the author who first minted the very term: Thomas More.

2. Although the challenging question remains for philosophers and scientists adhering to the emergentist perspective to answer: in what regards is the notion of emergence ultimately distinguishable and novel compared to the notion of formal cause - the form or essence of a thing - and material cause as wrought out by Aristotle (Chapter 2)? In fact, in Aristotle's line of argumentation there was no doubting that a thing - for example, a brain or a hand - was composed by smaller elements that materially constitute it (material cause), but that the same material elements in a different order are not the thing - a brain or a hand - because it is only in that order (which is the form or essence) that they are indeed. Emergentism may be a philosophical perspective attuned to accommodating the implicit world-view of the contemporary man/woman, who takes the discoveries of the modern natural sciences as a self-evident 'starting point' (something which obviously the ancient Greek did not), but whether the notion of emergence is a novel concept, or one which may displace the notion of essence or causal form, this is far from evident.

3. We have seen in Chapter 3 how our German philosopher aimed at incorporating all the epochs of human history and philosophical thought into progressively superior syntheses, placing his own philosophy at the top.

4. It seems they are also more complicated in the natural sciences and notably in physics, where developments over the 20th century have challenged many previously held assumptions. Quantum physics refers to 'distribution of probability of presence' of particles, whose combined 'position plus movement' can never be determined with a precision superior to the limit posed by the constant of Planck: the very notion of 'presence' seems to be shattered. Shifting from the extremely 
small to the extremely big, Albert Einstein's theory of relativity poses a limit to the causal influence: an object 'present' can only influence those possible future events that are within the reach of the speed of the light departing from the object; beyond that limit, an object cannot wield an influence, cannot perform as a cause.

5. It goes without saying, in the presence of a necessitating cause, an effect will by definition follow of necessity - but the issue here is whether the totality of reality and history is ultimately governed by the category of necessity or by that of possibility.

6. Even if the inquiry eventually led the investigator to formulate propositions in the form of probabilistic causation, perhaps because nothing better could be found due to limits to our methods.

7. See https://www.gov.uk/government/publications/civil-service-code/the-civil-ser vice-code (accessed 21 October 2019). 